\title{
Rho GTPases as therapeutic targets in cancer (Review)
}

\author{
G.A. CARDAMA, N. GONZALEZ, J. MAGGIO, P. LORENZANO MENNA and D.E. GOMEZ \\ Laboratory of Molecular Oncology, Department of Science and Technology, \\ Quilmes National University, Bernal B1876BXD, Buenos Aires, Argentina \\ Received May 16, 2017; Accepted July 17, 2017
}

DOI: $10.3892 /$ ijo.2017.4093

\begin{abstract}
Rho GTPases are key molecular switches controlling the transduction of external signals to cytoplasmic and nuclear effectors. In the last few years, the development of genetic and pharmacological tools has allowed a more precise definition of the specific roles of Rho GTPases in cancer. The aim of the present review is to describe the cellular functions regulated by these proteins with focus in deregulated signals present in malignant tumors. Finally, we describe the state of the art in search of different experimental therapeutic strategies with Rho GTPases as molecular targets.
\end{abstract}

\section{Contents}

1. Introduction

2. Structure and function

3. Main effectors of Rho GTPases

4. Role of Rho GTPases in cancer

5. Rho GTPases as therapeutic targets in cancer

6. Concluding remarks

\section{Introduction}

In the last decades, several signaling pathways have been identified as key molecular regulators of cell behavior, among them the Rho GTPases. The Rho family of GTPases is a family of small ( 21 kDa) monomeric $\mathrm{G}$ proteins that belong to the Ras superfamily of GTPases. The Ras superfamily of GTPases comprises more than 50 members that share several common features: their molecular weight (18-28 kDa), their C-terminal polyisoprenylation region and the property to bind to and hydrolyze guanine nucleotides (1).

Rho GTPases are key regulators of cytoskeletal structure and dynamics influencing cell adhesion, morphology and progression through the cell cycle. They act as a molecular

Correspondence to: Dr Daniel Gomez, Laboratory of Molecular Oncology, Quilmes National University, R. Sáenz Peña 352, Bernal B1876BXD, Buenos Aires, Argentina

E-mail: degomez@unq.edu.ar

Key words: cell signaling, Rho GTPase, cancer, inhibitors switch cycling between an inactive GDP-bound and an active GTP-bound state. The Rho GTPases form 8 subfamilies; one subfamily comprises Rac1, Rac2, Rac3 and RhoG; the second subfamily contains Cdc42, TC10 (also known as RhoQ) and TC10-like protein (TCL; also known as RhoJ); a third subfamily includes CHP (also known as RhoV) and WNT1responsive Cdc42 homologue-1 (WRCH1; also known as RhoU); a fourth subfamily involves RhoH; a fifth subfamily embraces RhoBTB1 and RhoBTB2; a sixth subfamily embodies RhoA, RhoB and RhoC; a seventh subfamily consists of RND1, RND2 and RND3 (also known as RhoE); and the last subfamily is composed by RAP1-interacting factor-1 (RIF; also known as RhoF) and RhoD (2).

\section{Structure and function}

Up to date three members of the Rho GTPase family have been studied in detail: Cdc42, Racl and RhoA. These are all the classical Rho GTPases that cycle between active GTP-bound forms and inactive GDP-bound forms.

The biological activities of Rho family GTPases are controlled by their guanine nucleotide binding states in a process dependent of $\mathrm{Mg}^{2+}$. In most cases, members of the Ras superfamily when they are in their active state, they transmit signals by binding to a specific set of proteins termed effectors, leading to a signaling cascade. The Rho GTPases have functional domains in common, similar to those of Ras. Such domains consist of four regions that take part in the binding and hydrolysis of guanine nucleotides (G1, G3, G4 and G5), a $\mathrm{G} 2$ region involved in the interaction with effectors (3) and a terminal CAAX box (being $\mathrm{C}$ a cysteine residue, $\mathrm{A}$ an aliphatic residue and $X$ any other amino acid) (4). The CAAX box acts as a signal for protein prenylation which involves the addition of $\mathrm{C}_{15}$ (farnesyl) or $\mathrm{C}_{20}$ (geranyl-geranyl), a phenomenon which is catalyzed by protein prenyl-transferases. Following prenylation, additional enzymatic processing including proteolysis and methylation occurs (5). While not as common, some Rho family members need the covalent addition of a palmitate acyl chain to their C-terminal hypervariable domain found immediately adjacent to the CAAX box. Similar to prenylation, palmitoylation plays a pivotal role in directing these Rho family members to membrane-associated states (6). Post-translational modifications do not affect GTPase activity but are essential for their biological function since they control their anchorage to cell membrane, therefore, their localization inside the cell (7). 
Rho proteins are highly regulated. There are three types of regulatory proteins: i) GEFs: which stands for guaninenucleotide exchange factors that catalyze the release of GDP and the subsequent uptake of GTP. ii) GAPs: (also known as GTPase-activating proteins or GTPase-accelerating proteins) are a family of regulatory proteins whose members can bind to activated $\mathrm{G}$ proteins and stimulate their GTPase activity, with the result of terminating the signaling event; and iii): GDIs or GDP-dissociation inhibitors which regulate the GDP/GTP exchange reaction of the Rho proteins by inhibiting the dissociation of GDP from them (8).

The small GTPases of the Rho family are master regulators of actin cytoskeleton rearrangements and cell morphology. RhoA can be activated by extracellular ligands (such as lysophosphatidic acid) and its activation results in the assembly of stress fibers and focal adhesion complexes. Racl is activated in response to various stimuli including growth factors such as platelet-derived growth factor (PDGF), epidermal growth factor (EGF) or insulin, leading to lamellipodia formation and the constitution of a motile cell surface that contains a meshwork of newly polymerized actin filaments known as membrane ruffling or cell ruffling. Racl also plays a pivotal role in promoting the formation of nascent focal complexes (9).

Integrin-mediated cell-extracellular matrix adhesion activates Rac1, which directly binds and activates p21-activated kinases (PAKs) and other effectors including phosphatidylinositol-4-phosphate 5-kinase, Nap125, PIR121 and IRSp53, resulting in increased membrane protrusions and actin polymerization. On the other hand, activated $\mathrm{Cdc} 42$ phosphorylates PAK1 and PAK2, which in turn lead to filopodia formation (10-13). These changes either by themselves or integrated can affect gene expression, cell cycle progression and apoptosis. Although, different cell processes are modulated by Rho GTPases, it is important to highlight that the cellular events are regulated by integrated signaling networks and not by a single signaling cascade. Then, the same stimuli in different cell contexts could produce different responses.

An example of cross talk between Rho GTPases and other regulating pathways is the regulation of Rac1-GAP $\beta 2$-chimaerin by the protein kinase C (PKC). Rac1-GAPs $\beta 2$-chimaerins are activated by the lipid second messenger diacylglycerol upon activation of tyrosine kinase receptors. It has been described that epidermal growth factor (EGF) causes rapid phosphorylation of $\beta 2$-chimaerin via $\mathrm{PKC} \delta$ retaining it in the cytosol and preventing its translocation to membranes (14). Also, there is evidence of intercommunication between the different Rho GTPases, whereas RhoA and Rac1 regulate each other, then modulating different cell processes $(15,16)$.

\section{Main effectors of Rho GTPases}

Approximately $1 \%$ of the human genome encodes proteins that either regulate or are regulated by interactions with members of the Rho family of small GTPases. The wide variety of biological functions of the different members of the Rho GTPases is due to the binding to different effectors. More than 50 effectors of RhoA, Racl and Cdc 42 are known including serine-threonine kinases, tyrosine-kinases, lipidkinases, lipases, oxidases and structural proteins (scaffold proteins) (17)
At least two Rho effectors have been studied in detail: the Rho-associated protein kinases (ROCKs) and the formin mDia1 (mammalian homolog of the Drosophila Diaphanous protein) (18). ROCK1 and ROCK2 share 65\% overall homology and $92 \%$ homology in the kinase domain (19). Both are serine/ threonine kinases that are downstream targets of the small GTPases RhoA, RhoB and RhoC. Structurally they contain a catalytic kinase domain at the N-terminus, a central coiledcoil domain, which includes the Rho-binding domain (RBD) and a C-terminal pleckstrin-homology $(\mathrm{PH})$ domain. ROCKs are involved in diverse cellular activities including actin cytoskeleton organization, cell adhesion and motility, proliferation, apoptosis, remodeling of the extracellular matrix (ECM) and smooth muscle cell contraction. Formins also regulate the actin and microtubule cytoskeleton and are involved in various cellular functions such as cell polarity, cytokinesis, cell migration and serum response factor (SRF) transcriptional activity. Some formins can contain a GTPase-binding domain (GBD) required to bind to Rho GTPases and a C-terminal conserved DRF auto-regulatory domain (Dia-autoregulatory domain or DAD). The GBD domain is a bifunctional auto-inhibitory domain that interacts with and is regulated by activated Rho family members. DAD induces actin filament formation, stabilizes microtubules and activates serum-response mediated transcription (20).

On the other hand, effector proteins of Cdc42 as WASP (Wiskott-Aldrich syndrome protein) and N-WASP are involved in the formation of filopodia. WASP is only expressed in hematopoietic cells. N-WASP, which is ubiquitously expressed, shares around 50\% homology with WASP. Both proteins possess several domains: a $\mathrm{PH}$ domain that binds phosphatidylinositol $(4,5)$ bisphosphate, a Cdc42-binding (GBD) domain, a proline-rich region, a $\mathrm{G}$-acting binding verprolin homology (V) domain, a domain (C) with homology to the actin-depolymerizing protein cofilin and finally a C-terminal acidic segment. Both WASP and N-WASP induce actin polymerization when overexpressed in fibroblasts. WASP proteins bind directly to acting monomers and activate the Arp2/3 complex; they comprise a core mechanism that directly connects signal transduction pathways to the stimulation of acting polymerization (21).

Furthermore, Rac1 is also able to activate the Arp2/3 complex and this is one of the core regulatory pathways driving membrane protrusion. Activation of WAVE (WASP-like verprolin-homologous protein) complex requires simultaneous interactions with prenylated Rac1-GTP and acidic phospholipids, as well as a specific state of phosphorylation. Together, these signals promote full activation in a highly cooperative process leading to the formation of lamellipodia. Also another major effector of both Rac1 and Cdc42 is PAK1. PAK1 phosphorylates LIM-kinase at threonine 508 within LIM-kinase's activation loop, increasing LIM-kinase-mediated phosphorylation of the actin-regulatory protein cofilin. Activated GTPases can thus regulate actin depolymerization through PAK1 and LIM-kinase modulating microfilaments length (22).

Another process regulated by Rho GTPases is the intracellular organization of microtubules, playing a central role in cell polarity and mitotic spindle assembly (23). The microtubule tip protein CLIP-170 interacts with the Cdc42/Rac1 effector IQGAP and mediates transient capture of microtubules. 
IQGAP1 is a scaffold protein essential for cellular signaling in response to external cues, linking dynamic microtubules to steer cell migration via interacting with the plus-end tracking protein SKAP (24).

It is important also to point out the role played by stathmin which is crucial for the regulation of the microtubule cytoskeleton. Stathmin interacts with two molecules of dimeric $\alpha$ - and $\beta$-tubulin to form a tight ternary complex called the T2S complex. When stathmin sequesters tubulin into the T2S complex, tubulin becomes non-polymerizable. Without tubulin polymerization, there is no microtubule assembly. Stathmin also promotes microtubule disassembly by acting directly on the microtubule ends. Regulation of stathmin is cell cycle-dependent and controlled by the cell's protein kinases in response to specific cell signals. Stathmin phosphorylation increases the concentration of tubulin available in the cytoplasm for microtubule assembly. For cells to assemble the mitotic spindle, stathmin phosphorylation must occur. At cytokinesis, the last phase of the cell cycle, rapid dephosphorization of stathmin occurs to block the cell from entering back into the cell cycle until it is ready (25).

In addition to their cytoskeletal effects, Rho GTPases regulate several signal transduction pathways that lead to alterations in gene expression affecting several transcription factors such as SRF, NF- $\kappa \mathrm{B}, \mathrm{JNK}$ (c-jun N-terminal kinase) and p38 MAP kinase (17).

Also, Rho GTPases are able to modulate different enzymatic activities. For instance, Rac1 plays a crucial role in activation of Nox family NADPH oxidases in enzymes dedicated to production of reactive oxygen species such as superoxide. The phagocyte oxidase Nox2, crucial for microbicidal activity during phagocytosis, is activated in a Rac1-dependent manner. Rac1 in the GTP-bound form directly binds to the oxidase activator p67 (PHOX), which in turn interacts with NOX2, leading to superoxide production $(26,27)$.

Furthermore, Rho GTPases have also been shown to regulate cell cycle entry and cell cycle progression, in particular by regulating expression of a number of genes involved in $\mathrm{G} 1 / \mathrm{S}$ transition, such as cyclin D1 or p21waf1. Rho GTPases are also critically involved in mitosis. Indeed, at mitosis onset, RhoA activity increases and the resulting activation of its effector ROCK, mediates cortical retraction during mitotic cell rounding. During early mitosis, depending on the cell type, either the GEF-H1/RhoA/mDial or the Ect $2 / \mathrm{Cdc} 42 / \mathrm{mDia} 3$ pathways are needed for spindle assembly and attachment of microtubules to kinetochores. Later in mitosis, Rho GTPases are directly involved in cytokinesis by regulating the actin and myosin contractile ring, which eventually forms the cleavage furrow to separate daughter cells (28).

It is important to highlight that cells perceive their microenvironment not only through soluble signals but also through physical and mechanical cues, such as ECM stiffness or confined adhesiveness. By mechano-transduction systems, cells translate these stimuli into biochemical signals controlling multiple aspects of cell behavior, but how rigidity sensing is ultimately linked to activity of nuclear transcription factors just started to be understood. Downstream events involving Rho GTPases in response to cytoskeleton tensioning include activation of YAP (yes-associated protein) and TAZ (transcriptional coactivator with PDZ binding motif) transcriptional regulators as nuclear relays of mechanical signals exerted by ECM rigidity and cell shape (29).

\section{Role of Rho GTPases in cancer}

In every physiological process each signaling element has an exquisite temporal and spatial regulation; at the same time deregulated expression leads to the development of many diseases among them cancer, the focal point of the present study (30). As mentioned, Rho GTPases through a series of complex biochemical networks control some of the most fundamental processes of the cell. Mutations or alterations of this complex signaling system could lead to cancer development. Traditionally, overactivation of the Rho GTPase pathways has been associated with malignant transformation. Recently, it has been described in a gain-of-function mutation in the racl gene in sun-exposed melanomas, although racl has been rarely found mutated in other human cancers (30-32). Rac1 upregulation is mostly due to alterations of its regulatory proteins. Notably, GEF activation is the most common mechanism for signal-mediated GTPase activation. This activation is commonly driven by aberrant signaling from growth factor receptors (RTKs) and GPCRs (G protein coupled receptors) and upregulation or mutation of GEFs (33). In this regard, many GEFs present a relevant role in cancer such as Ect2, Tiam1, Vav family, P-Rex1, DOCK family among others (34-37).

First evidence of malignant transformation by Rho GTPases was provided by experiments where constitutively activated Rac1, and in a lesser extent RhoA, induced malignant transformation in fibroblasts and tumorigenicity in athymic mice $(38,39)$. In line with this idea, Rac1 is implicated in epithelial-mesenchymal transition and in mesenchymalepithelial transition (40-43). Currently, alterations in the Rho GTPase pathways can be found in many cancer types. Among them we can mention malignant tumors of pancreas, breast, skin, prostate, testicle, colon, liver, lung, stomach as well as in leukemia, osteosarcoma, neuroblastoma, glioblastoma and head and neck cancer (44-47). Although Rho GTPase overexpression is commonly observed in cancer, downregulation of some Rho family members has also been linked to cancer (48).

Loss of cell polarity is a hallmark of cancer, with the loss of epithelial cell polarity being common among carcinoma cells $(49,50)$. For cells to keep their polarity, cell-to-cell contact must be maintained, being Rac1, RhoA and Cdc42 indispensable for keeping a normal state (51). Regarding cell motility the Rho/ROCK pathway plays a central role in the acquisition of migratory and invasive properties in tumor cells (52), since they are implicated in the remodeling of the actin cytoskeleton, in intracellular adhesion mediated by cadherins and in the remodeling of the extracellular matrix (ECM) primarily by the release of matrix metalloproteinases (MMP), mainly MMP-9 (53).

It has been found that Racl is a key protein in the invasive process of pediatric medulloblastoma (54). In models of glioblastoma multiforme Rac1, Rac3 and some GEFs mediate the migratory and invasive capacity of these tumors $(36,55,56)$.

Once a tumor is established, neovascularization of the pathological tissue is essential (57). In vitro and in vivo studies have identified Rho proteins as essential in signaling for vascular endothelial growth factor (VEGF)-dependent 
capillary formation (58). Regarding the regulatory proteins of the GTPases involved in cancer, one of the most studied examples is the Rac1-GEF Tiam1 (T-cell lymphoma invasion and metastasis 1). Although GTPases are not considered oncogenes, Tiam1 was confirmed as one, since it is implicated in the oncogenic transformation of fibroblasts $(59,60)$. The Tiam1 gene was identified by insertional mutagenesis in a model of $\mathrm{T}$ cell lymphoma, carrying out an in vitro selection of highly invasive clones. In this way it was established that Tiam1 increases the invasive capacity and the metastatic potential of tumor cells (59). Additionally, Tiam1 levels are increased and could be correlated with the prognosis of human prostate carcinomas, nasopharyngeal carcinomas and with the degree of progression of breast tumors (61).

In line with this idea, Vav1, another Rac1 GEF, is overexpressed in pancreatic adenocarcinoma and metastatic melanoma (62).

Also, the expression levels of Rac1-GAP $\beta 2$-chimaerin are significantly diminished in mammary tumors (63). Furthermore, it has been shown that overexpression of $\beta 2$-chimaerin in a murine mammary carcinoma model produces the reduction of tumor growth rate and its invasive and metastatic capacity (64).

Another hallmark exhibited by cancer cells is the limitless replicative potential that is mainly due to the activity of telomerase. This holoenzyme maintains telomere length, adding TTAGGG repetitions at the end of chromosomes in each cell division (65). In addition to this function, there are extratelomeric roles of telomerase that are involved in cancer promoting events (66). It has been shown that telomerase reconstitution increased fibroblast migration through activation of CXCL12/CXCR4 axis and Rho family proteins (67).

Yeh et al (68) demonstrated that Cdc42/Rac1 participates in the control of telomerase activity in human nasopharyngeal cancer cells (NPC-076). They investigated the effects of inhibiting Cdc42 and Rac1 on the telomerase activity on cells. Treatment of NPC-076 cells with antisense oligonucleotides against $\mathrm{Cdc} 42$ or Rac1 produced an inhibition of telomerase activity. Similarly, transient expression of dominant-negative mutants of $\mathrm{Cdc} 42$ or Rac1, also produced an inhibition of telomerase activity in NPC-076 cells. This inhibition of telomerase activity was not associated with a transcriptional downregulation of hTERT, the key regulator of telomerase (69). This suggests that $\mathrm{Cdc} 42 / \mathrm{Racl}$ participate in the post-transcriptional control of telomerase activity in NPC-076 cells. It also was founded that RAC3 overexpression is required to maintain telomerase activity (70). Further analysis suggested that exogenous expression of hTERT may promote invasiveness and metastasis through upregulation of MMP9 and RhoC (71).

Since telomerase is a key target against cancer, many molecules have been developed against it. Lately, it has been postulated that telomerase regulation could be better than direct inhibition itself (72). It remains to know if Rho GTPases could exert this action in a more effective way that the ones that are known so far.

Stathmin is also a protein of clinical relevance in cancer. Stathmin's role in regulation of the cell cycle causes it to be oncoprotein 18 (op18). Op18/stathmin can cause uncontrolled cell proliferation when mutated and not functioning properly. If stathmin is unable to bind to tubulin, it allows for constant microtubule assembly and therefore constant mitotic spindle assembly. With no regulation of the mitotic spindle, the cell cycle is capable of cycling uncontrollably resulting in the unregulated cell growth characteristic of cancer cells (73).

Among the many different effectors of Rho GTPases, four of them are directly related with malignant transformation mediated by Rho proteins. First, we can mention the WASP family, effectors of Rac1 and Cdc42, related with actin cytoskeleton rearrangements, therefore associated to cell migration, filopodia, podosomes as well as membrane ruffles regulation. Another described effector is IQGAP, which by its interaction with Racl and Cdc42 is implicated in membrane ruffles and in the cell-cell unions mediated by E-cadherin $(74,75)$.

Thirdly, we should mention that the role of PAK in cancer has been widely described. They have more than 40 possible different substrates and mediate biological processes such as cell proliferation, cell motility and survival, angiogenesis and substrate-independent growth, among others (76). It has been described that by Rac1 activation, PAK1 is able to activate PKC $\gamma$, a necessary event for the interaction with the actinbundling protein fascin, mediating cell migration in a model of human colon carcinoma (77).

Finally, ROCK1 directly interacts with and stabilizes the oncogene c-Myc protein leading to the increased oncomir miR-17-92 cluster expression in breast cancer and prostate cancer (78); ROCK family members are direct effectors also of RhoA (79).

It is important to highlight that Rac1 may also drive anti-tumorigenic effects (80). Recently Zandvakili et al (81) reviewed the role of Rho GTPases with potential tumor suppressing roles, however, most of that data emerged from cancer genomic studies. In those studies the concept of mutation penetrance and expressivity have been not sufficiently analyzed to be conclusive about the subject (82). In any case, the redundant function among Rho GTPases, their many regulators and effectors added to the interplays of feedback signaling loops may explain such contradictions.

Although we just gave an overview on how different Rho-GTPases and their associated proteins may play a defined role in cancer, it should be taken into account that given the overlap between its physiological and pathological functions as well as its often contrasting effects in cellular processes, these different molecules could be, at times, playing a similar role.

\section{Rho GTPases as therapeutic targets in cancer}

The substantial body of evidence that relates Rho GTPases with cancer has made them an attractive therapeutic target at the molecular level. With an incredible level of complexity and as more knowledge was being incorporated to the true nature of Rho GTPases, many groups started the search of inhibitors that could influence negatively the characteristics of tumor cell growth. Some strategies used to develop inhibitors are shown in Fig. 1 and described below.

Targeting Rho-GEF interactions. Disrupting Rho interactions with specific GEFs represents an attractive therapeutic avenue. 


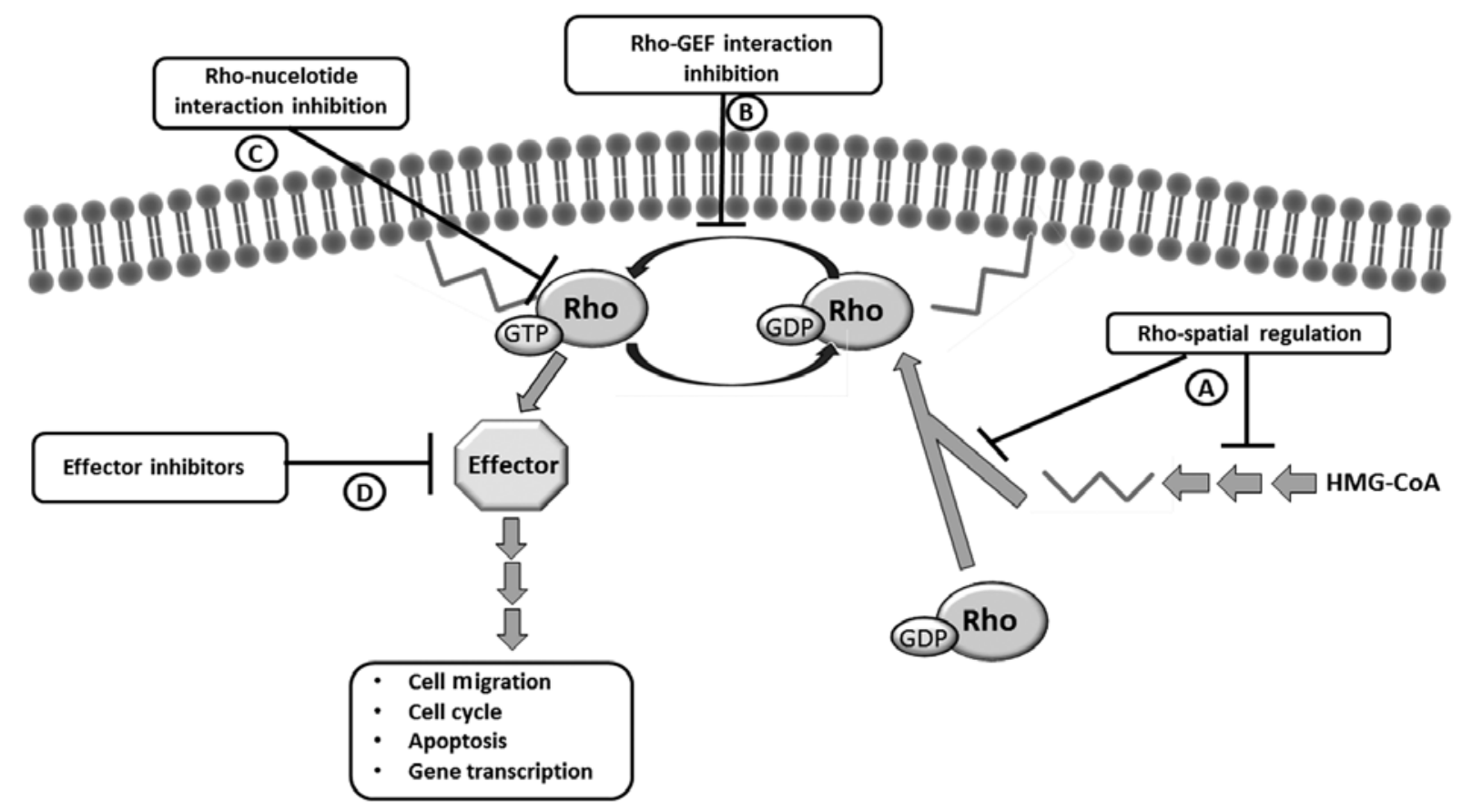

Figure 1. Different strategies to interfere with Rho-GTPase signaling pathway. A, Reduce isoprenoid precursors using statins or inhibition of farnesyl-transferases and geranylgeranyl transferases interfering with the prenylation of Rho GTPases, regulating spatial localization of the GTPase proteins. B, Activation cycle inhibition, by interfering Rho-GEF interaction. C, Interfering Rho-nucleotide binding. D, Direct inhibition of Rho GTPase effectors.

The first compound to be characterized was NSC23766 (83). It acts by inhibiting Rac1 activation by blocking the association of Rac1 and Tiam1 as well as Racl and Trio, another GEF. NSC23766 has been shown to inhibit pro-tumorigenic effects in a number of cancer models (84). NSC23766 suppressed the cell migration and growth of gefitinib-resistant nonsmall cell lung cancer (NSCLC) cells (85). Regarding breast cancer, treatment with trastuzumab improves outcomes for ErbB2-positive tumors; many patients who achieve an initial response to trastuzumab subsequently acquire resistance. Dokmanovic et al (86) demonstrated that NSC23766 restores trastuzumab-mediated endocytic downregulation of ErbB2 in vitro. Also, NSC23766 enhanced the antineoplastic effects of erlotinib in glioblastoma cell lines (87). Despite the promising results associated with NSC23766, this compound lacks the efficacy required for clinical purposes. Optimization of NSC23766 led to the identification of a potent Rac1 inhibitor, EHop-016 which functions through interfering Rac1-Vav2 binding and has been shown to suppress Racl cell migration of cancer cells (88).

Also by virtual screening, we identified in our laboratory a compound able to interfere with Rac1-GEF binding called ZINC69391. Further in vitro validation demonstrated that the compound interferes with Rac1-Tiam1 binding (89). Inhibition of Rac1 by ZINC69391 was also associated with efficient inhibition of cell cycle progression, cell proliferation and migration in highly metastatic breast cancer cell lines. Even more important in vivo use of ZINC69391 significantly reduced cancer lung metastasis in a breast cancer metastasis mouse model. Also, using ZINC69391 as a lead compound we identified a more potent analogue, $1 \mathrm{~A}-116$ also with in vitro and in vivo antimetastatic properties. Further analysis of 1A-116 indicated that it exerts its effects through interfering with Rac1-P-Rex1 binding and suppressing Racl activation. As known, one of the signs of tumor progression in breast and prostate cancer is the transition from being hormone-dependent to hormoneindependent, with the consequent resistance to antihormonal treatments; therefore, we also analyzed the effect of 1A-116 in tamoxifen resistant breast cancer cells. Deregulation of survival signaling pathways play a key role in tamoxifen resistance, being upregulation of Rac1-PAK1 signaling pathway one of the most important. We developed a breast cancer cell model (MCF7::C1199) having Rac1 enhanced activity. These cells not only showed distinctive features of Rac1-regulated processes as increased migration and proliferation rates, but also showed that upregulation of Racl activity triggered a hormonal-independent and tamoxifen resistant phenotype. We also demonstrated that PAK1 activity raises in response to tamoxifen, increasing phosphorylation levels of estrogen receptor at Ser305, a key phosphorylation site involved in tamoxifen resistance. 1A-116 effectively restored tamoxifen anti-proliferative effects, switched off PAK1 activity and decreased estrogen receptor phospho-Ser305 levels (90). Furthermore, PAK and the GEF AND-34 could be involved in the hormone-independence of mammary tumors $(91,92)$. This data support the use of antihormonal therapies combined with Rac1 inhibitors in the above-mentioned tumors.

We also analyzed the effect of both the parental molecule and the derived 1A-116 in malignant gliomas, whereas deregulation of small GTPases signaling, in particular Racl activity, plays a key role in their invasive phenotype. We reported that ZINC69391 on human glioma cell lines was able to interfere with the interaction of Rac1 with Dock180, a relevant Rac1 activator in glioma invasion, and to reduce Rac1-GTP levels. Pak1 was also downregulated upon ZINC69391 treatment. ZINC69391 reduced cell proliferation, affected cell migra- 
tion and invasion in vitro; interfering with actin cytoskeleton, arrested cells in G1 phase and triggered apoptosis in glioma cells. We also evaluated the effect of 1A-116, which showed an even greater antiproliferative and anti-invasive activity on glioma cells (93). Currently, we are carrying out preclinical testing in animal models of glioma with promising results (data not shown). Rho GTPases are also associated with increased invasive potential of glioblastomas after radiotherapy. The possibility has been proposed of inhibiting pharmacologically the Rac1 pathways with the aim of increasing the therapeutic efficacy of radiotherapy (94-96).

Additionally, CASIN has been described as a Cdc42 inhibitor that disrupts its interaction of its GEF intersectin (97). More selective Cdc42 inhibitors as ML141 (98) and ZCL278 (99) have been published and are under evaluation.

Other approaches include the identification by virtual screening of Rhosin, which binds to the surface of RhoA by Trp58 and blocks Rho-A-mediated cytoskeletal activity and invasiveness of breast cancer cells (100).

Targeting Rho-nucleotide interactions. Another important class of inhibitors includes compounds that specifically interfere with Racl nucleotide binding. Few drugs were developed in this area, and even less showed an effective action. The best example in this group is the well characterized EHT 1864 which displaces bound nucleotides resulting in an inert and inactive Rac1 state, which prevents GEF-mediated nucleotide exchange as well as Rac1 binding to downstream effectors, effectively blocking transformation mediated by constitutively active Rac1 (101).

Recently, Arnst et al (102) demonstrated two new compounds, referred in their publication as \#1 and \#6, that were design to target the nucleotide-binding site of Rac1 although, were able to block active Racl from binding to its effector PAK1, following EGF-induced Rac1 activation in a dose-dependent manner, they showed no inhibition of $\mathrm{Cdc} 42$ or RhoA. Functional studies indicated that both compounds reduced cell proliferation and migration in a dose-dependent manner in multiple pancreatic cancer cell lines at micromolar concentrations.

Targeting Rho spatial regulation. Since Rho proteins require the post-translational addition of lipid residues in their carboxyterminal region, a number of compounds have been developed with the intention of preventing such modification. In this group we can find farnesyl-transferase and geranylgeranyltransferase inhibitors. These compounds were demonstrated to have a high antitumor effect and several of them are in clinical trials (103).

Statins is a class of inhibitors that by inhibiting the HMG CoA reductase pathway simultaneously inhibit the production of both cholesterol and specific prenylated proteins, diminishing cholesterol levels and the lipid modifications needed by Rho GTPases. A possible disadvantage of isoprenylation inhibition is the low selectivity found among the different GTPases. However, clinical trials indicate that statins do affect tumor progression $(104,105)$. Recent data showed a prenylation-independent mode of action in which the protective effects of statins were attributed to the degradation of the nuclear pool of Rac1 (106) implicated in regulating cell cycle progression (107) and actin polymerization in the nucleus (108). Therefore, by stimulating nuclear Rac1 degradation, the protective effects of statins might also be a direct consequence of suppressing nuclear Rac1. For example, an analysis of nuclear Rac1 expression in cervical pre-malignant biopsies indicated increased expression in biopsies with lowgrade squamous intraepithelial lesions (SIL) and high grade SIL. Also, nuclear Rac1 was observed in cervical cancer cell lines but not in their normal counterparts suggesting a role of nuclear Rac1 in disease progression (109). It was also shown that Rac1 nuclear accumulation mediates tumor cell invasion due to increased RhoA signaling in the cytoplasm.

Other compounds which interfere with spatial regulation are GGTase I inhibitors (GGTs) which inhibit protein prenylation. Inhibition of GGTase I in a mouse model of pancreatic cancer was associated with reduced tumor growth in relation with the inhibition of protein geranyl-geranylation (110). Similar effects were found in a mouse model of lung cancer (111). GGTI-2418 has entered phase I clinical trials, but results have not been released yet (112). A number of inhibitors of palmitoylation have been developed and can be found in the study of Draper et al (113). However, the therapeutic potential of these compounds is yet to be demonstrated.

Targeting specific Rho downstream effectors. Other strategies used has been the inhibition of the effector proteins. Both ROCK inhibitors Y-27632 and fasudil bind the ATP-binding pocket of ROCK1 and ROCK2 and inhibit serine-threonine kinase activity $(114,115)$. They demonstrated a significant beneficial effect in many types of malignancies (116). Furthermore, it has been reported that the use of Y-27632 could diminish the neurotoxicity caused by antitumor drugs such as cisplatin (117). Fasudil was approved in Japan in 1995 for the prevention and treatment of cerebral vasospasm after surgery in subarachnoid hemorrhagic patients (118). Other competitive inhibitor of ROCK, Wf-536 was demonstrated to be an inhibitor of angiogenesis, tumor growth and metastasis in vivo (119).

Because these ROCK inhibitors are non-isoform specific also inhibit other serine/threonine kinases such as PKA and PKC at higher concentrations, so it may cause off-target effects (120). Efforts have been recently dedicated to the development of ROCK isoform selective inhibitors and several compounds have been reported (121). Despite the numerous ROCK inhibitors developed, there is only one reported clinical trial using ROCK inhibitors in cancer treatment: AT13148 in phase I initiated in 2012 for the treatment of advanced solid tumors (122).

Targeting RhoGTPases by other mechanisms. Azathioprine and its metabolite 6-Mercaptopurine are widely used as immunosuppressing drugs. Its mechanism of action was elucidated, proposing Racl as a specific target in T lymphocytes (123). Later it was found that the drug and its metabolite were able to diminish the active Rac1 levels in a model of murine mammary carcinoma in vitro (124). Recently, the phytochemical agent rocaglamide, which belongs to the family of flavaglines, was found to inhibit the activities of Rho, Cdc42 and Racl and that it could represent a new class of anticancer drugs (125). 


\section{Concluding remarks}

The redundancy and plasticity of the different pathways allow tumor cells to adapt and to overcome different difficult conditions either of therapeutic or environmental origin, implying that therapies with a unique highly specific target not always reach the levels of efficacy that are desirable. That suggests that different concomitant therapeutic strategies may be needed (126). An option is to combine drugs that modulate multiple signaling pathways. The most effective combinations may include agents that inhibit survival signals in multiple signal transduction pathways.

Targeting Rho GTPases represent a very interesting therapeutic opportunity. As shown, several inhibitors have been developed. While some of these compounds show promising results, it is evident that more potent inhibitors are yet to be identified. However, advancements in rational drug design together with our expanding knowledge of the mechanisms involved in regulating Rho GTPases signaling pave the way toward the development of highly specific and context dependent Rho-GTPase inhibitors.

\section{Acknowledgements}

Georgina Cardama is a D-TEC Fellow from ANPCyT, Nazareno Gonzalez is a Conicet Fellow and Julian Maggio is an INC fellow. Pablo Lorenzano Menna and Daniel Gomez are members of Conicet. The present study has been financed by the Universidad Nacional de Quilmes, ANPCyT and CONICET.

\section{References}

1. Marei $\mathrm{H}$ and Malliri A: Rac1 in human diseases: The therapeutic potential of targeting Racl signaling regulatory mechanisms. Small GTPases: Jul 21, 2016 (Epub ahead of print). doi: 10.1080/21541248.2016.1211398.

2. Feltri ML, Suter U and Relvas JB: The function of RhoGTPases in axon ensheathment and myelination. Glia 56: 1508-1517, 2008

3 . Wuichet K and Søgaard-Andersen L: Evolution and diversity of the Ras superfamily of small GTPases in prokaryotes. Genome Biol Evol 7: 57-70, 2014.

4. Ramos S, Khademi F, Somesh BP and Rivero F: Genomic organization and expression profile of the small GTPases of the RhoBTB family in human and mouse. Gene 298: 147-157, 2002.

5. Leung KF, Baron R, Ali BR, Magee AI and Seabra MC: Rab GTPases containing a CAAX motif are processed post-geranylgeranylation by proteolysis and methylation. J Biol Chem 282: 1487-1497, 2007.

6. Aicart-Ramos C, Valero RA and Rodriguez-Crespo I: Protein palmitoylation and subcellular trafficking. Biochim Biophys Acta 1808: 2981-2994, 2011.

7. Shinde SR and Maddika S: Post translational modifications of Rab GTPases. Small GTPases: Feb 28, 2017 (Epub ahead of print). doi: 10.1080/21541248.2017.1299270.

8. Ulu A and Frost JA: Regulation of RhoA activation and cytoskeletal organization by acetylation. Small GTPases 7: 76-81, 2016.

9. Martin E, Ouellette MH and Jenna S: Rac1/RhoA antagonism defines cell-to-cell heterogeneity during epidermal morphogenesis in nematodes. J Cell Biol 215: 483-498, 2016.

10. Sahai E and Marshall CJ: RHO-GTPases and cancer. Nat Rev Cancer 2: 133-142, 2002.

11. Takai Y, Sasaki T and Matozaki T: Small GTP-binding proteins. Physiol Rev 81: 153-208, 2001.

12. Kjøller L and Hall A: Signaling to Rho GTPases. Exp Cell Res 253: 166-179, 1999.

13. Symons M: The Rac and Rho pathways as a source of drug targets for Ras-mediated malignancies. Curr Opin Biotechnol 6: 668-674, 1995
14. Griner EM, Caino MC, Sosa MS, Colón-González F, Chalmers MJ, Mischak $\mathrm{H}$ and Kazanietz MG: A novel crosstalk in diacylglycerol signaling: The Rac-GAP $\beta 2$-chimaerin is negatively regulated by protein kinase Cdelta-mediated phosphorylation. J Biol Chem 285: 16931-16941, 2010.

15. Bustos RI, Forget MA, Settleman JE and Hansen SH: Coordination of Rho and Rac GTPase function via p190B RhoGAP. Curr Biol 18: 1606-1611, 2008.

16. Rosenfeldt H, Castellone MD, Randazzo PA and Gutkind JS: Rac inhibits thrombin-induced Rho activation: Evidence of a Pak-dependent GTPase crosstalk. J Mol Signal 1: 8-8, 2006.

17. Jaffe $A B$ and Hall A: Rho GTPases: Biochemistry and biology. Annu Rev Cell Dev Biol 21: 247-269, 2005.

18. Kyrkou A, Soufi M, Bahtz R, Ferguson C, Bai M, Parton RG, Hoffmann I, Zerial M, Fotsis T and Murphy C: RhoD participates in the regulation of cell-cycle progression and centrosome duplication. Oncogene 32: 1831-1842, 2013.

19. Wei L, Surma M, Shi S, Lambert-Cheatham N and Shi J: Novel insights into the roles of Rho kinase in cancer. Arch Immunol Ther Exp (Warsz) 64: 259-278, 2016.

20. Bartolini F, Moseley JB, Schmoranzer J, Cassimeris L, Goode BL and Gundersen GG: The formin mDia2 stabilizes microtubules independently of its actin nucleation activity. J Cell Biol 181: 523-536, 2008.

21. Reicher B, Joseph N, David A, Pauker MH, Perl O and BardaSaad M: Ubiquitylation-dependent negative regulation of WASp is essential for actin cytoskeleton dynamics. Mol Cell Biol 32: 3153-3163, 2012.

22. Ohashi K, Nagata K, Maekawa M, Ishizaki T, Narumiya S and Mizuno K: Rho-associated kinase ROCK activates LIM-kinase 1 by phosphorylation at threonine 508 within the activation loop. J Biol Chem 275: 3577-3582, 2000.

23. Lian G and Sheen VL: Cytoskeletal proteins in cortical development and disease: Actin associated proteins in periventricular heterotopia. Front Cell Neurosci 9: 99, 2015.

24. Malarkannan S, Awasthi A, Rajasekaran K, Kumar P, Schuldt KM, Bartoszek A, Manoharan N, Goldner NK, Umhoefer CM and Thakar MS: IQGAP1: A regulator of intracellular spacetime relativity. J Immunol 188: 2057-2063, 2012.

25. Belletti B and Baldassarre G: Stathmin: A protein with many tasks. New biomarker and potential target in cancer. Expert Opin Ther Targets 15: 1249-1266, 2011.

26. Bishop AL and Hall A: Rho GTPases and their effector proteins. Biochem J 348: 241-255, 2000.

27. Miyano $\mathrm{K}$ and Sumimoto $\mathrm{H}$ : Assessment of the role for Rho family GTPases in NADPH oxidase activation. Methods Mol Biol 827: 195-212, 2012.

28. David M, Petit D and Bertoglio J: Cell cycle regulation of Rho signaling pathways. Cell Cycle 11: 3003-3010, 2012.

29. Dupont S, Morsut L, Aragona M, Enzo E, Giulitti S, Cordenonsi M, Zanconato F, Le Digabel J, Forcato M, Bicciato S, et al: Role of YAP/TAZ in mechanotransduction. Nature 474: 179-183, 2011.

30. Porter AP, Papaioannou A and Malliri A: Deregulation of Rho GTPases in cancer. Small GTPases 7: 123-138, 2016

31. Hodis E, Watson IR, Kryukov GV, Arold ST, Imielinski M, Theurillat JP, Nickerson E, Auclair D, Li L, Place C, et al: A landscape of driver mutations in melanoma. Cell 150: 251-263, 2012.

32. Krauthammer M, Kong Y, Ha BH, Evans P, Bacchiocchi A, McCusker JP, Cheng E, Davis MJ, Goh G, Choi M, et al: Exome sequencing identifies recurrent somatic RAC1 mutations in melanoma. Nat Genet 44: 1006-1014, 2012.

33. Rossman KL, Der CJ and Sondek J: GEF means go: Turning on RHO GTPases with guanine nucleotide-exchange factors. Nat Rev Mol Cell Biol 6: 167-180, 2005.

34. Fields AP and Justilien V: The guanine nucleotide exchange factor (GEF) Ect2 is an oncogene in human cancer. Adv Enzyme Regul 50: 190-200, 2010.

35. Vigil D, Cherfils J, Rossman KL and Der CJ: Ras superfamily GEFs and GAPs: Validated and tractable targets for cancer therapy? Nat Rev Cancer 10: 842-857, 2010.

36. Jarzynka MJ, Hu B, Hui KM, Bar-Joseph I, Gu W, Hirose T, Haney LB, Ravichandran KS, Nishikawa R and Cheng SY: ELMO1 and Dock180, a bipartite Rac1 guanine nucleotide exchange factor, promote human glioma cell invasion. Cancer Res 67: 7203-7211, 2007.

37. Wertheimer E, Gutierrez-Uzquiza A, Rosemblit C, LopezHaber C, Sosa MS and Kazanietz MG: Rac signaling in breast cancer: A tale of GEFs and GAPs. Cell Signal 24: 353-362, 2012. 
38. Khosravi-Far R, Solski PA, Clark GJ, Kinch MS and Der CJ: Activation of Rac1, RhoA, and mitogen-activated protein kinases is required for Ras transformation. Mol Cell Biol 15: 6443-6453, 1995.

39. Qiu RG, Chen J, McCormick F and Symons M: A role for Rho in Ras transformation. Proc Natl Acad Sci USA 92: 11781-11785, 1995.

40. Sahai E and Marshall CJ: Differing modes of tumour cell invasion have distinct requirements for Rho/ROCK signalling and extracellular proteolysis. Nat Cell Biol 5: 711-719, 2003.

41. Wolf K, Mazo I, Leung H, Engelke K, von Andrian UH, Deryugina EI, Strongin AY, Bröcker EB and Friedl P Compensation mechanism in tumor cell migration: Mesenchymal-amoeboid transition after blocking of pericellular proteolysis. J Cell Biol 160: 267-277, 2003.

42. Nakaya Y, Kuroda S, Katagiri YT, Kaibuchi K and Takahashi Y: Mesenchymal-epithelial transition during somitic segmentation is regulated by differential roles of Cdc42 and Rac1. Dev Cell 7: 425-438, 2004.

43. Lv Z, Hu M, Zhen J, Lin J, Wang Q and Wang R: Rac1/PAK1 signaling promotes epithelial-mesenchymal transition of podocytes in vitro via triggering $\beta$-catenin transcriptiona activity under high glucose conditions. Int J Biochem Cell Biol 45: 255-264, 2013

44. Fritz G, Just I and Kaina B: Rho GTPases are over-expressed in human tumors. Int J Cancer 81: 682-687, 1999.

45. Engers R, Ziegler S, Mueller M, Walter A, Willers R and Gabbert HE: Prognostic relevance of increased Rac GTPase expression in prostate carcinomas. Endocr Relat Cancer 14: 245-256, 2007.

46. Lin Y and Zheng Y: Approaches of targeting Rho GTPases in cancer drug discovery. Expert Opin Drug Discov 10: 991-1010, 2015.

47. Gómez del Pulgar T, Benitah SA, Valerón PF, Espina C and Lacal JC: Rho GTPase expression in tumourigenesis: Evidence for a significant link. BioEssays 27: 602-613, 2005.

48. Liu Y, Song N, Ren K, Meng S, Xie Y, Long Q, Chen X and Zhao X: Expression loss and revivification of RhoB gene in ovary carcinoma carcinogenesis and development. PLoS One 8: e78417, 2013.

49. Karlsson R, Pedersen ED, Wang Z and Brakebusch C: Rho GTPase function in tumorigenesis. Biochim Biophys Acta 1796 91-98, 2009.

50. Royer C and Lu X: Epithelial cell polarity: A major gatekeeper against cancer? Cell Death Differ 18: 1470-1477, 2011.

51. Joyce JA and Pollard JW: Microenvironmental regulation of metastasis. Nat Rev Cancer 9: 239-252, 2009.

52. Parri M and Chiarugi P: Rac and Rho GTPases in cancer cell motility control. Cell Commun Signal 8: 23-23, 2010.

53. Mackay AR, Gomez DE, Nason AM and Thorgeirsson UP: Studies on the effects of laminin, E-8 fragment of laminin and synthetic laminin peptides PA22-2 and YIGSR on matrix metalloproteinases and tissue inhibitor of metalloproteinase expression. Lab Invest 70: 800-806, 1994

54. Zavarella S, Nakada M, Belverud S, Coniglio SJ, Chan A, Mittler MA, Schneider SJ and Symons M: Role of Racl-regulated signaling in medulloblastoma invasion. Laboratory investigation. J Neurosurg Pediatr 4: 97-104, 2009.

55. Salhia B, Tran NL, Chan A, Wolf A, Nakada M, Rutka F, Ennis M, McDonough WS, Berens ME, Symons M, et al The guanine nucleotide exchange factors trio, Ect2, and Vav3 mediate the invasive behavior of glioblastoma. Am J Pathol 173: 1828-1838, 2008.

56. Chan AY, Coniglio SJ, Chuang YY, Michaelson D, Knaus UG, Philips MR and Symons M: Roles of the Rac1 and Rac3 GTPases in human tumor cell invasion. Oncogene 24: 7821-7829, 2005.

57. de Lorenzo MS, Ripoll GV, Yoshiji H, Yamazaki M, Thorgeirsson UP, Alonso DF and Gomez DE: Altered tumor angiogenesis and metastasis of B16 melanoma in transgenic mice overexpressing tissue inhibitor of metalloproteinases-1. In Vivo 17: 45-50, 2003.

58. Bryan BA and D'Amore PA: What tangled webs they weave: Rho-GTPase control of angiogenesis. Cell Mol Life Sci 64: 2053-2065, 2007.

59. Habets GG, van der Kammen RA, Stam JC, Michiels F and Collard JG: Sequence of the human invasion-inducing TIAM1 gene, its conservation in evolution and its expression in tumor cell lines of different tissue origin. Oncogene 10: 1371-1376, 1995.
60. van Leeuwen FN, van der Kammen RA, Habets GG and Collard JG: Oncogenic activity of Tiam1 and Rac1 in NIH3T3 cells. Oncogene 11: 2215-2221, 1995.

61. Li Z, Liu Q, Piao J, Hua F, Wang J, Jin G, Lin Z and Zhang Y: Clinicopathological implications of Tiam1 overexpression in invasive ductal carcinoma of the breast. BMC Cancer 16: 681, 2016.

62. Razidlo GL, Magnine C, Sletten AC, Hurley RM, Almada LL, Fernandez-Zapico ME, Ji B and McNiven MA: Targeting pancreatic cancer metastasis by inhibition of Vav1, a driver of tumor cell invasion. Cancer Res 75: 2907-2915, 2015.

63. Yang C, Liu Y, Leskow FC, Weaver VM and Kazanietz MG: Rac-GAP-dependent inhibition of breast cancer cell proliferation by \{beta\}2-chimerin. J Biol Chem 280: 24363-24370, 2005.

64. Menna PL, Skilton G, Leskow FC, Alonso DF, Gomez DE and Kazanietz MG: Inhibition of aggressiveness of metastatic mouse mammary carcinoma cells by the beta2-chimaerin GAP domain. Cancer Res 63: 2284-2291, 2003.

65. Gomez DE, Armando RG and Alonso DF: AZT as a telomerase inhibitor. Front Oncol 2: 113, 2012.

66. Armando RG, Gomez DM and Gomez DE: AZT exerts its antitumoral effect by telomeric and non-telomeric effects in a mammary adenocarcinoma model. Oncol Rep 36: 2731-2736, 2016.

67. Qu Y, Mao M, Li X, Zhang L, Huang X, Yang C, Zhao F, Xiong Y and Mu D: Enhanced migration and CXCR4 over-expression in fibroblasts with telomerase reconstitution. Mol Cell Biochem 313: 45-52, 2008

68. Yeh YM, Pan YT and Wang TC: Cdc42/Rac1 participates in the control of telomerase activity in human nasopharyngeal cancer cells. Cancer Lett 218: 207-213, 2005.

69. Gomez DLM, Armando RG, Cerrudo CS, Ghiringhelli PD and Gomez DE: Telomerase as a cancer target. Development of new molecules. Curr Top Med Chem 16: 2432-2440, 2016.

70. Fernández Larrosa PN, Ruíz Grecco M, Mengual Gómez D, Alvarado CV, Panelo LC, Rubio MF, Alonso DF, Gómez DE and Costas MA: RAC3 more than a nuclear receptor coactivator: A key inhibitor of senescence that is downregulated in aging. Cell Death Dis 6: e1902, 2015.

71. Chen PC, Peng JR, Huang L, Li WX, Wang WZ, Cui ZQ, Han H, Gong L, Xiang DP, Qiao SS, et al: Overexpression of human telomerase reverse transcriptase promotes the motility and invasiveness of HepG2 cells in vitro. Oncol Rep 30: 1157-1164, 2013.

72. Gómez DL, Farina HG and Gómez DE: Telomerase regulation: A key to inhibition? (Review). Int J Oncol 43: 1351-1356, 2013.

73. Cassimeris L: The oncoprotein 18/stathmin family of microtubule destabilizers. Curr Opin Cell Biol 14: 18-24, 2002.

74. Tyler JJ, Allwood EG and Ayscough KR: WASP family proteins, more than Arp2/3 activators. Biochem Soc Trans 44: 1339-1345, 2016.

75. Choi S and Anderson RA: IQGAP1 is a phosphoinositide effector and kinase scaffold. Adv Biol Regul 60: 29-35, 2016.

76. Dummler B, Ohshiro K, Kumar R and Field J: Pak protein kinases and their role in cancer. Cancer Metastasis Rev 28: 51-63, 2009.

77. Parsons $\mathrm{M}$ and Adams JC: Rac regulates the interaction of fascin with protein kinase C in cell migration. J Cell Sci 121: 2805-2813, 2008.

78. Wei L, Surma M, Shi S, Lambert-Cheatham N and Shi J: Novel insights into the roles of Rho kinase in cancer. Arch Immunol Ther Exp (Warsz) 64: 259-278, 2016.

79. Rattan S and Singh J: RhoA/ROCK pathway is the major molecular determinant of basal tone in intact human internal anal sphincter. Am J Physiol Gastrointest Liver Physiol 302: G664-G675, 2012.

80. Dawson JC, Bruche S, Spence HJ, Braga VM and Machesky LM: Mtss1 promotes cell-cell junction assembly and stability through the small GTPase Rac1. PLoS One 7: e31141, 2012.

81. Zandvakili I, Lin Y, Morris JC and Zheng Y: Rho GTPases: Antior pro-neoplastic targets. Oncogene 36: 3213-3222, 2017.

82. Cooper DN, Krawczak M, Polychronakos C, Tyler-Smith C and Kehrer-Sawatzki H: Where genotype is not predictive of phenotype: Towards an understanding of the molecular basis of reduced penetrance in human inherited disease. Hum Genet 132: 1077-1130, 2013 
83. Gao Y, Dickerson JB, Guo F, Zheng J and Zheng Y: Rational design and characterization of a Rac GTPase-specific small molecule inhibitor. Proc Natl Acad Sci USA 101: 7618-7623, 2004.

84. Bid HK, Roberts RD, Manchanda PK and Houghton PJ: RAC1: An emerging therapeutic option for targeting cancer angiogenesis and metastasis. Mol Cancer Ther 12: 1925-1934, 2013.

85. Kaneto N, Yokoyama S, Hayakawa Y, Kato S, Sakurai H and Saiki I: RAC1 inhibition as a therapeutic target for gefitinibresistant non-small-cell lung cancer. Cancer Sci 105: 788-794 2014.

86. Dokmanovic M, Wu Y, Shen Y, Chen J, Hirsch DS and Wu WJ: Trastuzumab-induced recruitment of Csk-homologous kinase $(\mathrm{CHK})$ to ErbB2 receptor is associated with ErbB2-Y1248 phosphorylation and ErbB2 degradation to mediate cell growth inhibition. Cancer Biol Ther 15: 1029-1041, 2014.

87. Karpel-Massler G, Westhoff MA, Kast RE, Dwucet A, Karpel-Massler S, Nonnenmacher L, Siegelin MD, Wirtz CR, Debatin KM and Halatsch ME: Simultaneous interference with HER1/EGFR and RAC1 signaling drives cytostasis and suppression of survivin in human glioma cells in vitro. Neurochem Res 42: 1543-1554, 2017.

88. Montalvo-Ortiz BL, Castillo-Pichardo L, Hernández E, Humphries-Bickley T, De la Mota-Peynado A, Cubano LA Vlaar CP and Dharmawardhane S: Characterization of EHop-016, novel small molecule inhibitor of Rac GTPase. J Biol Chem 287: 13228-13238, 2012.

89. Cardama GA, Comin MJ, Hornos L, Gonzalez N, Defelipe L, Turjanski AG, Alonso DF, Gomez DE and Menna PL: Preclinica development of novel Rac1-GEF signaling inhibitors using a rational design approach in highly aggressive breast cancer cell lines. Anticancer Agents Med Chem 14: 840-851, 2014.

90. Gonzalez N, Cardama GA, Comin MJ, Segatori VI, Pifano M, Alonso DF, Gomez DE and Menna PL: Pharmacological inhibition of Rac1-PAK1 axis restores tamoxifen sensitivity in human resistant breast cancer cells. Cell Signal 30: 154-161, 2017.

91. Felekkis KN, Narsimhan RP, Near R, Castro AF, Zheng Y, Quilliam LA and Lerner A: AND-34 activates phosphatidylinositol 3-kinase and induces anti-estrogen resistance in a $\mathrm{SH} 2$ and GDP exchange factor-like domain-dependent manner. Mo Cancer Res 3: 32-41, 2005.

92. Cai D, Iyer A, Felekkis KN, Near RI, Luo Z, Chernoff J, Albanese C, Pestell RG and Lerner A: AND-34/BCAR3, a GDP exchange factor whose overexpression confers antiestrogen resistance, activates Rac, PAK1, and the cyclin D1 promoter. Cancer Res 63: 6802-6808, 2003.

93. Cardama GA, Gonzalez N, Ciarlantini M, Gandolfi Donadío L, Comin MJ, Alonso DF, Menna PL and Gomez DE: Proapoptotic and antiinvasive activity of Rac1 small molecule inhibitors on malignant glioma cells. Onco Targets Ther 7: 2021-2033, 2014.

94. Hwang SY, Jung JW, Jeong JS, Kim YJ, Oh ES, Kim TH, Kim JY, Cho KH and Han IO: Dominant-negative Rac increases both inherent and ionizing radiation-induced cell migration in C6 rat glioma cells. Int J Cancer 118: 2056-2063, 2006.

95. Delmas C, Heliez C, Cohen-Jonathan E, End D, Bonnet J, Favre G and Toulas C: Farnesyltransferase inhibitor, R115777, reverses the resistance of human glioma cell lines to ionizing radiation. Int J Cancer 100: 43-48, 2002.

96.Zhai GG, Malhotra R, Delaney M, Latham D, Nestler U, Zhang M, Mukherjee N, Song Q, Robe P and Chakravarti A Radiation enhances the invasive potential of primary glioblastoma cells via activation of the Rho signaling pathway. J Neurooncol 76: 227-237, 2006.

97. Florian MC, Dörr K, Niebel A, Daria D, Schrezenmeier H, Rojewski M, Filippi MD, Hasenberg A, Gunzer M, Scharffetter-Kochanek K, et al: Cdc42 activity regulates hematopoietic stem cell aging and rejuvenation. Cell Stem Cell 10: 520-530, 2012.

98. Hong L, Kenney SR, Phillips GK, Simpson D, Schroeder CE, Nöth J, Romero E, Swanson S, Waller A, Strouse JJ, et al Characterization of a Cdc42 protein inhibitor and its use as a molecular probe. J Biol Chem 288: 8531-8543, 2013.

99. Friesland A, Zhao Y, Chen YH, Wang L, Zhou H and Lu Q: Small molecule targeting Cdc42-intersectin interaction disrupts Golgi organization and suppresses cell motility. Proc Natl Acad Sci USA 110: 1261-1266, 2013.

100. Shang X, Marchioni F, Sipes N, Evelyn CR, JerabekWillemsen M, Duhr S, Seibel W, Wortman M and Zheng Y: Rational design of small molecule inhibitors targeting RhoA subfamily Rho GTPases. Chem Biol 19: 699-710, 2012.
101. Shutes A, Onesto C, Picard V, Leblond B, Schweighoffer F and Der CJ: Specificity and mechanism of action of EHT 1864, a novel small molecule inhibitor of Rac family small GTPases. J Biol Chem 282: 35666-35678, 2007.

102. Arnst JL, Hein AL, Taylor MA, Palermo NY, Contreras JI, Sonawane YA, Wahl AO, Ouellette MM, Natarajan A and Yan Y: Discovery and characterization of small molecule Racl inhibitors. Oncotarget 8: 34586-34600, 2017.

103. Mazieres J, Pradines A and Favre G: Perspectives on farnesyl transferase inhibitors in cancer therapy. Cancer Lett 206 . 159-167, 2004

104. Chan KK, Oza AM and Siu LL: The statins as anticancer agents. Clin Cancer Res 9: 10-19, 2003.

105. Farina HG, Bublik DR, Alonso DF and Gomez DE: Lovastatin alters cytoskeleton organization and inhibits experimental metastasis of mammary carcinoma cells. Clin Exp Metastasis 19: 551-559, 2002

106. Tanaka S, Fukumoto Y, Nochioka K, Minami T, Kudo S, Shiba N, Takai Y, Williams CL, Liao JK and Shimokawa H Statins exert the pleiotropic effects through small GTP-binding protein dissociation stimulator upregulation with a resultant Racl degradation. Arterioscler Thromb Vasc Biol 33: 1591-1600, 2013.

107. Michaelson D, Abidi W, Guardavaccaro D, Zhou M, Ahearn I, Pagano M and Philips MR: Racl accumulates in the nucleus during the $\mathrm{G} 2$ phase of the cell cycle and promotes cell division. J Cell Biol 181: 485-496, 2008.

108. Navarro-Lérida I, Pellinen T, Sanchez SA, Guadamillas MC, Wang Y, Mirtti T, Calvo E and Del Pozo MA: Rac1 nucleocytoplasmic shuttling drives nuclear shape changes and tumor invasion. Dev Cell 32: 318-334, 2015.

109. Mendoza-Catalán MA, Cristóbal-Mondragón GR, AdameGómez J, del Valle-Flores HN, Coppe JF, Sierra-López L, Romero-Hernández MA, del Carmen Alarcón-Romero L, Illades-Aguiar B and Castañeda-Saucedo E: Nuclear expression of Rac1 in cervical premalignant lesions and cervical cancer cells. BMC Cancer 12: 116-116, 2012.

110. Lu J, Chan L, Fiji HDG, Dahl R, Kwon O and Tamanoi F: In vivo antitumor effect of a novel inhibitor of protein geranylgeranyltransferase-I. Mol Cancer Ther 8: 1218-1226, 2009.

111. Zimonjic DB, Chan LN, Tripathi V, Lu J, Kwon O, Popescu NC, Lowy DR and Tamanoi F: In vitro and in vivo effects of geranylgeranyltransferase I inhibitor P61A6 on non-small cell lung cancer cells. BMC Cancer 13: 198-198, 2013.

112. Berndt N, Hamilton AD and Sebti SM: Targeting protein prenylation for cancer therapy. Nat Rev Cancer 11: 775-791, 2011.

113. Draper JM, Xia Z and Smith CD: Cellular palmitoylation and trafficking of lipidated peptides. J Lipid Res 48: 1873-1884, 2007.

114. Nagumo H, Sasaki Y, Ono Y, Okamoto H, Seto M and Takuwa Y: Rho kinase inhibitor HA-1077 prevents Rho-mediated myosin phosphatase inhibition in smooth muscle cells. Am J Physiol Cell Physiol 278: C57-C65, 2000.

115. Uehata M, Ishizaki T, Satoh H, Ono T, Kawahara T, Morishita T, Tamakawa H, Yamagami K, Inui J, Maekawa M, et al: Calcium sensitization of smooth muscle mediated by a Rho-associated protein kinase in hypertension. Nature 389: 990-994, 1997.

116. Kale VP, Hengst JA, Desai DH, Amin SG and Yun JK: The regulatory roles of ROCK and MRCK kinases in the plasticity of cancer cell migration. Cancer Lett 361: 185-196, 2015.

117. James SE, Burden H, Burgess R, Xie Y, Yang T, Massa SM, Longo FM and Lu Q: Anti-cancer drug induced neurotoxicity and identification of Rho pathway signaling modulators as potential neuroprotectants. Neurotoxicology 29: 605-612, 2008

118. Dong M, Yan BP, Liao JK, Lam YY, Yip GWK and Yu CM Rho-kinase inhibition: A novel therapeutic target for the treatment of cardiovascular diseases. Drug Discov Today 15: 622-629, 2010

119. Fritz G and Kaina B: Rho GTPases: Promising cellular targets for novel anticancer drugs. Curr Cancer Drug Targets 6: 1-14, 2006.

120. Bain J, Plater L, Elliott M, Shpiro N, Hastie CJ, McLauchlan H, Klevernic I, Arthur JS, Alessi DR and Cohen P: The selectivity of protein kinase inhibitors: A further update. Biochem J 408 297-315, 2007

121. Boerma M, Fu Q, Wang J, Loose DS, Bartolozzi A, Ellis JL, McGonigle S, Paradise E, Sweetnam P, Fink LM, et al: Comparative gene expression profiling in three primary human cell lines after treatment with a novel inhibitor of Rho kinase or atorvastatin. Blood Coagul Fibrinolysis 19: 709-718, 2008. 
122. Sadok A, McCarthy A, Caldwell J, Collins I, Garrett MD, Yeo M, Hooper S, Sahai E, Kuemper S, Mardakheh FK, et al: Rho kinase inhibitors block melanoma cell migration and inhibit metastasis. Cancer Res 75: 2272-2284, 2015.

123. Tiede I, Fritz G, Strand S, Poppe D, Dvorsky R, Strand D, Lehr HA, Wirtz S, Becker C, Atreya R, et al: CD28-dependent Rac1 activation is the molecular target of azathioprine in primary human CD4+ T lymphocytes. J Clin Invest 111: 1133-1145, 2003.

124. Menna PL, Parera RL, Cardama GA, Alonso DF, Gomez DE and Farina HG: Enhanced cytostatic activity of statins in mouse mammary carcinoma cells overexpressing $\beta 2$-chimaerin. Mol Med Rep 2: 97-102, 2009
125. Becker MS, Müller PM, Bajorat J, Schroeder A, Giaisi M, Amin E, Ahmadian MR, Rocks O, Köhler R, Krammer PH, et al: The anticancer phytochemical rocaglamide inhibits Rho GTPase activity and cancer cell migration. Oncotarget 7: 51908-51921, 2016.

126. Dent P, Curiel DT, Fisher PB and Grant S: Synergistic combinations of signaling pathway inhibitors: Mechanisms for improved cancer therapy. Drug Resist Updat 12: 65-73, 2009. 